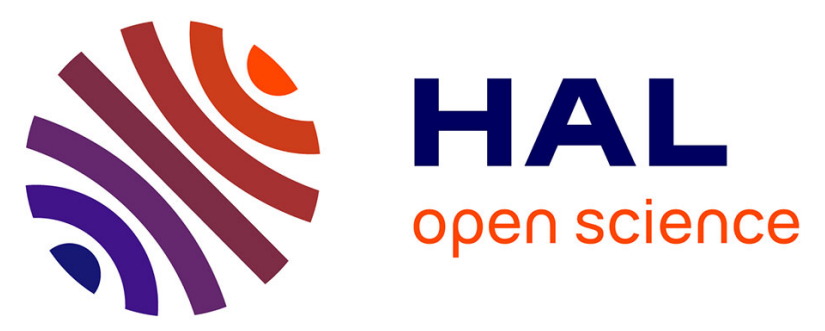

\title{
The gene responsible for Dyggve-Melchior-Clausen syndrome encodes a novel peripheral membrane protein dynamically associated with the Golgi apparatus
}

Ariane Dimitrov, Vincent Paupe, Charles Gueudry, Jean-Baptiste Sibarita, Graça Raposo, Ole Vielemeyer, Thierry Gilbert, Zsolt Csaba, Tania Attié-Bitach, Valérie Cormier-Daire, et al.

\section{To cite this version:}

Ariane Dimitrov, Vincent Paupe, Charles Gueudry, Jean-Baptiste Sibarita, Graça Raposo, et al.. The gene responsible for Dyggve-Melchior-Clausen syndrome encodes a novel peripheral membrane protein dynamically associated with the Golgi apparatus. Human Molecular Genetics, 2009, 18 (3), pp.440-453. 10.1093/hmg/ddn371 . hal-02342676

\section{HAL Id: hal-02342676 \\ https://hal.science/hal-02342676}

Submitted on 2 Jun 2020

HAL is a multi-disciplinary open access archive for the deposit and dissemination of scientific research documents, whether they are published or not. The documents may come from teaching and research institutions in France or abroad, or from public or private research centers.
L'archive ouverte pluridisciplinaire HAL, est destinée au dépôt et à la diffusion de documents scientifiques de niveau recherche, publiés ou non, émanant des établissements d'enseignement et de recherche français ou étrangers, des laboratoires publics ou privés. 


\title{
The gene responsible for Dyggve-Melchior-Clausen syndrome encodes a novel peripheral membrane protein dynamically associated with the Golgi apparatus
}

\begin{abstract}
Ariane Dimitrov ${ }^{3,6, *}$, Vincent Paupe ${ }^{1 *}$, Charles Gueudry ${ }^{3,6}$, Jean-Baptiste Sibarita ${ }^{3,6}$, Graça Raposo $^{3,6}$, Ole Vielemeyer ${ }^{3,6}$, Thierry Gilbert ${ }^{4}$, Zsolt Csaba ${ }^{5}$, Tania Attie-Bitach ${ }^{2}$, Valérie Cormier $^{2}$, Pierre Gressens ${ }^{1}$, Pierre Rustin ${ }^{1}$, Franck Perez ${ }^{3,6, \$, \#}$, Vincent El Ghouzzi ${ }^{1 \S, \#}$
\end{abstract}

Short title: Dym, a novel disease-associated Golgi protein

Key words: DMC syndrome, Dymeclin, myristoylation, Golgi apparatus, FRAP, nocodazole

1- Unité INSERM U676, Physiopathologie et Neuroprotection des Atteintes du Cerveau en Développement, Hôpital Robert Debré, 75019 Paris, France

2- Unité INSERM U781, Handicaps Génétiques de l'Enfant, Hôpital Necker Enfants Malades, 75015 Paris, France

3- $\quad$ UMR CNRS 144, Institut Curie, 75005 Paris, France

4- Unité INSERM U574, Néphropathies Héréditaires et Rein en Développement, Hôpital Necker Enfants Malades, 75015 Paris, France

5- INSERM U686, Biologie des Jonctions Neuromusculaires Normales et Pathologiques, Université Paris Descartes75006 Paris France

6- $\quad$ Institut Curie - Centre de Recherches - 75005 Paris, France

$\S$ Correspondence should be addressed to:

- Vincent El Ghouzzi, INSERM U676 - Physiopathologie et Neuroprotection des Atteintes du Cerveau en Développement - Hôpital Robert Debré - 75019 Paris, France - Tel: +331 4003 1973 - Fax: +33140031978 - E-mail: vincent.elghouzzi@inserm.fr

- Franck Perez, CNRS UMR144, Institut Curie - 26, rue d'Ulm - 753248 Paris Cedex 05 France - Tel: +33156246388-Fax: +33156246319 - Email: Franck.Perez@curie.fr

$*$ and \# indicate equal contributions. 


\begin{abstract}
Dyggve-Melchior-Clausen dysplasia (DMC) is a rare inherited dwarfism with severe mental retardation due to mutations in the DYM gene which encodes Dymeclin, a 669-aminoacid protein of yet unknown function. Despite a high conservation across species and several predicted transmembrane domains, Dymeclin could not be ascribed to any family of proteins. Here we show, using in situ hybridization, that DYM is widely expressed in human embryos, especially in the cortex, the hippocampus and the cerebellum. Both the endogenous and the recombinant protein fused to GFP co-localized with Golgi apparatus markers. Electron microscopy revealed that Dymeclin associates with the Golgi apparatus and with transitional vesicles of the reticulum-Golgi interface. Moreover, permeabilization assays revealed that Dymeclin is not a transmembrane but a peripheral protein of the Golgi apparatus as it can be completely released from the Golgi after permeabilization of the plasma membrane. Time lapse confocal microscopy experiments on living cells further showed that the protein shuttles between the cytosol and the Golgi apparatus in a highly dynamic manner and recognizes specifically a subset of mature Golgi membranes. Finally, we found that DYM mutations associated with DMC result in mis-localization and subsequent degradation of Dymeclin. These data indicate that DMC results from a loss-of-function of Dymeclin, a novel peripheral membrane protein which shuttles rapidly between the cytosol and mature Golgi membranes and point out a role of Dymeclin in cellular trafficking.
\end{abstract}




\section{Introduction}

Dymeclin is a protein recently identified as the translation product of the FLJ20071/FLJ90130/Dym gene (DYM) which mutations are responsible for a severe autosomal-recessive skeletal dysplasia associated with mental delay, Dyggve-MelchiorClausen syndrome (DMC, MIM\#223800) and a clinical variant without mental impairment, Smith-McCort syndrome (SMC, MIM\#607326), (1 , 2). DMC/SMC skeletal features consist of a short trunk dwarfism with particular radiological features, severe proximal limb shortening and microcephaly associated with a peculiar facial dysmorphism (3). Mental retardation is consistently observed in DMC with an average IQ between 25 and 65. Children are often hyperactive, display autistic features and do not speak. Both skeletal and mental features are progressive in DMC, and the phenotype often leads to severe orthopedic complications (3).

Dymeclin is a 669-aminoacid protein which does not belong to any identified protein family. Except for five or six putative transmembrane domains and a N-terminal myristoylation site, search for predictive structural and/or functional motives failed to provide any clue as to the function of Dymeclin $(1,2)$. Most of the mutations identified in DYM predict the generation of a truncating product; however, a few frameshift mutations in the last exon predicting an elongated protein, two complex genomic duplications resulting in exon repetition, and two missense mutations have also been reported $(1,2,4)$. At the ultrastructural level, DMC cells disclose enlarged endoplasmic reticulum (ER) network and accretion of intracytosolic membranous vesicles $(2,3,5,6)$. It has therefore been proposed that Dymeclin may be an integral membrane protein of the ER possibly involved in the transport of intracellular compounds (7). Because the DMC phenotype resembles that of type IV mucopolysaccharidosis (Morquio disease), a lysosomal disorder due to either $\mathrm{N}$ acetylgalactosamine-6-sulfatase or $\beta$-galactosidase deficiency, it has also been hypothesized that Dymeclin has a role in intracellular digestion of proteins. However, the cellular phenotype of DMC rather evokes abnormal storage and/or membrane trafficking involving specifically the endoplasmic reticulum network. It therefore clearly differs from that of the Morquio disease in which ultrastructural anomalies involve lysosomes. In addition, biochemical analyses failed to reveal any enzymatic deficiency or accumulation of specific substrate in DMC cells (3).

In order to obtain additional clues about Dymeclin function, we studied the expression pattern of the DYM gene in human embryonic and foetal tissues using in situ hybridization and 


\section{Results}

\section{$D Y M$ transcripts are widely expressed during human development}

Northern blot analysis of mRNA derived from human tissues previously showed that DYM has two transcripts (3.1 and $5.6 \mathrm{~kb}$ ) abundantly expressed in foetal brain (2). Using two nonoverlapping riboprobes selected in either the 5'-half of DYM (probe A, $0.85 \mathrm{~kb}$ ) or its 3'-half (probe B, $0.5 \mathrm{~kb}$, not shown), we revealed the same two RNA species, thus confirming their specificity. We also show that $D Y M$ is abundantly expressed in primary chondrocytes and osteoblasts (Fig. 1A). Because mutations in DYM specifically affect the cognitive development of children and their bone growth in a progressive manner, we questioned whether DYM expression was specific to nervous and osseous tissues or if it was more widely expressed during human development. To address this question, a human multiple tissue expression array was probed with probe A. Consistent with a wide range of expression, DYM transcripts were detected in most adult tissues (Fig. 1A). Highest levels of expression were seen in the cerebellum, kidney, lung and stomach, but in the heart and the pancreas as well. However, very low or no expression was observed in the spleen, thymus, oesophagus, bladder and thyroid gland. DYM was also expressed in a variety of human cell types, including HeLa, $\mathrm{SaOs} 2$ and skin fibroblasts and was detected in murine ES cells (Fig. 1A).

As to investigate the spatio-temporal expression pattern of $D Y M$ during human development, we performed in situ hybridization on human embryonic and foetal tissues at different developmental stages, Carnegie Stage 17 (CS17, 40 day embryo), Carnegie Stage 19 (CS19, 47-48 day embryo), 17 and 22 weeks of gestation foetus. At CS17, expression of DYM was slightly detectable in numerous structures of the embryo, including the neural tube, the cranial nerve nuclei, the mandible, the stomach, and the limb bud, but no structure showed a particularly marked signal (data not shown). Hybridization at CS19 confirmed the widespread expression of $D Y M$ with a higher expression in the germinative zone of the prosencephalon, mesencephalon and cerebellum anlage (Fig. 1B, a,b,c) but also in mesenchymal condensations 
of the lung and intestinal epithelia (Fig. 1B, a,d,e,f,g). Surprisingly enough, no specific signal could be detected in the vertebrae of the CS19 embryo. Specific expression in the cerebellum was confirmed at later stages. In the 17 week cerebellum, DYM was mostly expressed in the external granule cell layer, the germinative zone which gives rise to the internal granule neurons between 16 and 40 weeks (Fig. 1B, h,i,j,k). At 22 weeks of age, DYM was highly expressed in the external granule layer, in the Purkinje neurons and in the internal granule layer (Fig. 1B, p,q,r,s). At both 17 and 22 weeks, specific labelling was observed in the neocortical plate and corresponding ventricular zone (germinative zone) as well as in the hippocampus (Fig. 1B, 1,m,n,o and t,u,v,w). No specific labelling was detected in areas of neuronal migration at any stage.

Together, these data show that human DYM expression is not restricted to nervous and osseous tissues but is also expressed in most embryo-foetal and adult tissues.

\section{The DYM gene product, Dymeclin, is a Golgi-associated protein}

The coding sequence of $D Y M$ is predicted to produce a 669 -aminoacid protein we have previously named Dymeclin (2). As to characterize Dymeclin, we generated a polyclonal antiserum against a 16-aminoacid peptide selected in the amino-terminal half of the protein in a region conserved between mouse and human. The sub-cellular localization of Dymeclin was assessed in HeLa cells by immunofluorescence. As shown in Figure 2A, we found endogenous Dymeclin in the cytosol but it was predominantly detected as a perinuclear pattern reminiscent of the Golgi complex. When cells were double-labelled for Dymeclin and GM130, a marker of the cis-Golgi, an extensive overlap was observed. Specificity of our antibody could be checked in immunofluorecence using a mis-localized mutant of Dymeclin (Fig.2A), although we did not detect a stronger Golgi labelling upon over-expression of exogenous Dymeclin, suggesting that Golgi localization may be saturable. We were also able to immunoprecipitate the recombinant protein fused to GFP at its carboxy-terminus, DymGFP ( 105kDa, Fig.2B). However, our antibody did not raise specific signal in western blot. Importantly, GFP-tagged Dymeclin was similarly found on Golgi elements. HeLa cells were transfected with Dym-GFP and stained for immunofluorescence using various markers of the cis-Golgi (GM130 and Giantin), the trans-Golgi/trans-Golgi Network (Galactosyl Transferase and TGN46) and of the endoplasmic reticulum (PDI, Fig. 4B). Like the endogenous protein, recombinant Dymeclin strongly co-localized with markers of the cis and trans-Golgi and was closely apposed to the TGN marker (Fig. 3A). By contrast, Dymeclin did not co-localize with markers of the endoplasmic reticulum (Fig. 4B). Similar results were obtained using an 


\section{Dymeclin is a peripheral Golgi protein}

Based of hydrophobic domain analysis, it has been proposed that Dymeclin may be a multispanning transmembrane protein (7). To address this question, we used a permeabilization assays in living cells adapted from a protocol described by Lorenz et al. (9). HeLa cells stably expressing mCherry-Histone were transfected with GFP-tagged Dymeclin and observed by fluorescent microscopy. Cells were then treated by low concentration of digitonin to permeabilize the plasma membrane and observed again. While Dym-GFP was present on the Golgi apparatus and in the cytosol before treatment, it completely disappeared after $1 \mathrm{~min}$ upon opening of the cells (Fig. 5). We compared Dymeclin behavior to ARF1 and GRASP65 behavior, two myristoylated proteins associated with the Golgi apparatus. Before treatment, Dymeclin, GRASP65 and ARF1 display very similar localization (Fig. 5 a,c,e). However, the 
Golgi apparatus was still weakly stained by GRASP65 and ARF1 1 minute after permeabilization (Fig. 5 e,f) suggesting that the association of ARF1-GFP and GRASP65GFP with the Golgi apparatus is more stable than that of Dymeclin. Because Dymeclin was more rapidly released from the Golgi apparatus than two well known peripheral Golgi proteins that dynamically exchange with the cytosol $(10,11)$, we concluded that Dymeclin is not a transmembrane protein but is a cytosolic protein which can be recruited to the Golgi apparatus.

\section{Dymeclin rapidly shuttles between the Golgi complex and the cytosol}

Because Dymeclin behaved as a peripherally associated Golgi protein and was also present in the cytosol, we next examined the dynamics of the protein in living cells. HeLa cells were transfected with GFP-tagged Dymeclin and fluorescence recovery after photobleaching (FRAP) experiments were performed on living HeLa cells 24 hours after transfection. GFPtagged ARF1 and GRASP65 were used as references for Golgi-associated myristoylated proteins. We measured the fraction of these proteins which is associated to the Golgi apparatus (Fig. 6A). As reported previously (10), we found that $16.5 \pm 4 \%$ of ARF1 is Golgiassociated. We obtained very similar values for Dymeclin $(13.6 \pm 3.9 \%)$ while a larger pool was measured for GRASP-65 (33.2 $\pm 10.8 \%)$. The recovery of fluorescence was quantified for the three proteins after correction of the photobleaching resulting from the acquisition and subtraction of the background. The quantifications were performed on $3 \mathrm{D}$ and $2 \mathrm{D}$ images and gave similar results (data not shown). We therefore decided to work with 2D images in order to increase the frequency of acquisition. The normalized intensity measured for 30 seconds after FRAP for all proteins was plotted on the same graph (Fig. 6B). When Golgi-associated Dym-GFP was photobleached, fluorescence recovered to the Golgi area in less than twenty seconds (Fig. 6D and sup. Movie 1); this recovery is faster than that of the two reference proteins (Fig. 6B). We calculated the mean half time of recovery and confirmed that DymGFP recovers more rapidly than the two other proteins with a half time of $2.8 \pm 0.9$ seconds (Fig. 6C). Arf1-GFP, which is known to be a fast shuttling protein $(10,11)$ displayed a halftime recovery of $7.1 \pm 2.6$ seconds while GRASP65-GFP had a slightly slower dynamics with a half-time of $12.4 \pm 4.5$ seconds. These results demonstrate that Dymeclin is a highly mobile protein as the entire Golgi pool can be exchanged in less than 20 seconds. 
Dymeclin specifically binds to a subset of the Golgi apparatus upon nocodazole treatment

We have shown in the past that depolymerization of microtubules by a nocodazole treatment reveals the presence of two separate Golgi pools (12). Most of Golgi-associated proteins (like GM130 and GalT) are relocated on the newly formed mini stacks that appear after microtubules disassembly whereas one protein, Giantin, is found only on the old, pre-existing Golgi complex that keeps its juxta-nuclear localization. This may be due to the fact that Giantin being a very large transmembrane protein is recycling very slowly to the newly formed mini-stacks. In order to test whether Dymeclin recognizes a particular set of Golgi stacks, HeLa cells expressing Dym-GFP were left untreated or incubated for 90 minutes in the presence of nocodazole, before being fixed and stained for GM130 and Giantin and observed by immunofluorescence. The three proteins strongly co-localized in control conditions (Fig. 7A, top line). After nocodazole treatment, and as reported before (12), GM130 was present on the mini stacks dispersed through the cytoplasm whereas Giantin was still located on "old" Golgi complexes that were present before nocodazole addition and that are still located in the pericentriolar region (Fig. 7A, bottom line). Surprisingly, Dym-GFP was present both as a soluble pool and on the "old" Golgi but not on the newly formed mini stacks. This result was very surprising as we have shown that Dym-GFP shuttles very rapidly between the Golgi apparatus and the cytosol and suggested that Dym-GFP specifically recognizes a subset of the Golgi apparatus. To test this hypothesis, we followed the dynamics of Dym-GFP after nocodazole treatment in living HeLa cells by FRAP. Cells were co-transfected with DymGFP and mCherry-GM130 and treated with nocodazole 24 hours after transfection (Fig. 7B). As expected, GM130 was found on dispersed dots in the cytoplasm while Dymeclin was preferentially located in a subset of cellular structures (see the GM130-positve element indicated by an arrowhead in Fig. 7B). Dym-GFP was photo-bleached and its recovery analyzed. White arrows in Figure 7B indicate the bleached region. Dym-GFP fluorescence had already largely recovered after 9 seconds (top line, Dym-GFP) whereas mCherry-GM130 did not recover during the time of acquisition (middle line, mCh-GM130). Therefore, Dymeclin specifically and dynamically recognizes a subset of the Golgi apparatus while it ignores other Golgi stacks, a behavior revealed in the absence of microtubules. 


\section{DMC mutations but not the E87K SMC mutation result in Dymeclin mis-localization and subsequent protein degradation}

Most of the genetic mutations which have been identified in DMC patients are stop mutations, insertions and deletions causing frameshift or splice mutations that predict protein truncation (3). However, one missense mutation (N469Y) has been identified in some DMC patients while another one $(\mathrm{E} 87 \mathrm{~K})$ has been associated with the SMC variant with no mental retardation $(1,2)$. Since mental retardation is variable in DMC (ranging from mild to severe), and totally absent in SMC, we asked whether the consequence of DYM mutations on the protein could differ between mutations. To this end, three nonsense mutations (R204X, Q483X and K616X) and the two missense mutations (N469Y and E87K) were introduced through site-directed mutagenesis in GFP-Dym. Following over-expression of these constructs in HeLa cells, the localization of the five mutant proteins was analyzed and compared to that of wild-type GFP-Dym and GM130. Although GFP fluorescence was globally found very weak in cells transfected with DMC mutations, numerous small aggregates were observed in many cells in a pattern suggestive of protein degradation (Fig. $8 \mathrm{~A})$. However cells transfected with the E87K mutation still displayed a pattern similar to that of the wild-type Dymeclin. Therefore, only DMC mutations resulted in a mis-localization and aggregation of Dymeclin. Since ubiquitin-rich cytoplasmic inclusion is linked to the pathogenesis of many diseases, we performed a double labelling of DMC mutants with an antibody raised against ubiquitin. As shown in Figure 8B, ubiquitin was found co-localized with mutant GFP-Dym aggregates. These results strongly suggest that DMC mutations result in intracellular deposition of mis-folded Dymeclin which then aggregates into ubiquitin-rich cytoplasmic inclusions, most likely inducing its degradation, whereas the E87K SMC mutation does not affect the stability and the location of the protein.

\section{Discussion}

\section{Dymeclin, a new peripheral protein of the Golgi apparatus}

The gene responsible for DMC syndrome encodes a 669-aminoacid protein we have named Dymeclin. BLASTS, sequence motif and homology searches using multiple databases indicated that Dymeclin is a novel evolutionarily conserved protein with no homology or known conserved functional domains, except for a putative $\mathrm{N}$-myristoylation site (2). Using electron microscopy and immunofluorescence techniques on both fixed and living cells, we have shown in this study that Dymeclin is a peripheral protein of the Golgi apparatus. We did 
not observe any significant ER labeling, which is in contrast with data obtained by Osipovich et al (13). However, these authors used an aminoterminally tagged Dymeclin, a tagging position which hampers myristoylation of the protein. Despite many trials with either homemade or commercially available antibodies (12 antibodies tested so far), specific signal for endogenous Dymeclin was hardly detectable in our hands by Western blot. This may be due to a poor ability of Dymeclin to elicit immune response or a high turn-over/instability of the protein in solution. However, we could detect a Golgi/cytosolic signal for many of the antiDym antibodies and immunoprecipitate Dym-GFP with one of them (see Fig. 2B). Based on the hydrophobicity profile of the aminoacid sequence, Dymeclin was first thought to be an integral membrane protein with six trans-membrane segments (1). Again, owing to the very fast release of Dymeclin from the Golgi (Fig. 6) we could not get conclusive results from classical biochemical fractionation. However, using imaging experiments, we have shown that Dymeclin is not a stably anchored trans-membrane protein but a dynamically localized peripheral protein of the Golgi apparatus. Firstly, short cell permeabilization without protein extraction using digitonin resulted in a complete loss of both soluble and Golgi-localized Dymeclin. In the same condition integral membrane proteins (not shown) but also well known Golgi peripheral proteins like ARF1 and GRASP65 were still membrane-associated. In addition, FRAP experiments revealed that Dymeclin shuttles very rapidly between the cytosol and the Golgi apparatus. Interestingly, it is the fastest Golgi shuttling protein described so far, exceeding the speed observed for ARF1 and GRASP65 (our results and $(14,15)$ ). Dymeclin is thus present as a cytosolic pool that can shuttle very rapidly between the cytosol and the Golgi apparatus, like other myristoylated proteins. However, the Golgi localization of ARF1 or GRASP65 depends on their myristoylation whereas Dymeclin as a second unknown mechanism of localization. Another striking difference which we report here is that while proteins like ARF1 or GRASP65 were not observed to select particular Golgi stacks, Dymeclin dynamically recognizes a subset of the Golgi apparatus revealed by the depolymerization of microtubules. The existence of two Golgi complex subsets was reported previously (12) but only Giantin was found to preferentially localize on the "old", preexisting, Golgi apparatus. That a shuttling protein like Dymeclin can similarly recognize the "old" Golgi suggests that it can recognize Golgi components specifically found at the surface of mature Golgi apparatus and not on newly formed mini-stacks (Fig. 9 B, green) in contrast to other shuttling proteins like ARF1 (Fig. 9 B, red). Both to understand the role of Dymeclin in disease development and to characterize further Golgi complex dynamics, it will be important to understand how Dymeclin can recognize a subset of the Golgi apparatus and if 
specific proteins or lipids are necessary for this localization. Because Giantin is a transmembrane protein of the Golgi apparatus, and is the only known marker of this mature Golgi compartment, it is tempting to speculate that Dymeclin is recruited on Golgi membranes by Giantin. Interestingly, Osipovich et al. identified Giantin as a potential Dymeclin partner by mass spectrophotometry analysis although this result has not be validated (13).

\section{DYM mutations lead to complete degradation of Dymeclin in DMC but not in SMC.}

Many mutations have been identified in DMC and SMC dysplasias which lie in various locations along the DYM gene (3). Although most of them predict protein truncation and a likely loss-of-function of Dymeclin, two different missense mutations have been associated specifically with DMC syndrome (N469Y, $(1,2))$ or SMC syndrome (E87K, $(1,2))$. Since mental retardation is constantly observed in DMC and absent in SMC, we asked whether these two specific amino-acid substitutions could result in different consequences on Dymeclin and found that the N469Y but not the E87K mutation results in mis-localization and subsequent protein degradation. So far, DYM mutations associated with SMC syndrome have been identified in only two families which share compound heterozygosity for the same two mutations, namely the E87K substitution (on one allele) and a splicing mutation leading to exon 8 skipping and a premature stop codon (on the other allele, $(1,2)$ ). Interestingly the latter mutation has been associated with DMC as well (3). Since heterozygous individuals who bear the exon 8 splice mutation plus one normal allele (like parents of these patients) are not affected, the E87K mutation appears specific to SMC phenotype. Given that this particular mutation neither results in Dymeclin degradation nor induces mis-localization, it is likely that some residual activity of Dymeclin could explain the absence of neurological phenotype in SMC patients. Conversely, since DMC and SMC share similar skeletal features, the E87K mutation likely exerts a deleterious effect in bony tissue. It will be interesting to identify the specific defects induced by the E87K mutation that prevent this Golgi-localized Dymeclin form to normally fulfill its function.

\section{What role for Dymeclin in DMC syndrome.}

Although skin anomalies are not part of the DMC phenotype, Dymeclin is present in fibroblasts and the ultrastructural anomalies observed in skin fibroblasts from DMC individuals presumably properly reflect the intracellular consequences of $D Y M$ deficiency (3). Indeed, electron microscopy analysis of chondrocytes from two children with Smith-McCort 
dysplasia (SMC) also revealed a highly dilated rough endoplasmic reticulum (6). From their observation, the authors concluded that SMC and DMC should be rough endoplasmic reticulum storage disorders. However, the specific compound which would accumulate does not seem to be Dymeclin itself since both nonsense and missense DMC mutations result in degradation of the protein. Several extensive biochemical analyses, including incorporation/degradation assays of sulphated proteoglycans, peroxysomal and lysosomal contents examination, lipid, carbohydrate and protein work up and assays of mitochondrial respiratory chain activities were performed by our group and others. However, no enzymatic deficiency or specific accumulated compound in DMC cells which would have been consistent with a specific storage of a putative mis-degraded metabolite could be found $(3,16$ $, 17,18,19)$. Although we can not rule out the possibility that DMC and SMC would be the consequence of a metabolic perturbation which we were unable to characterize yet, our data provide a body of arguments in favor of an ER-Golgi membrane trafficking disorder. However, experiments we carried out on DMC fibroblasts failed to reveal a reproducible defect in anterograde and retrograde membrane trafficking (data not shown). This may not be surprising because fibroblast cells are to affected in DMC patients. This is nevertheless in marked contrast with results reported by Osipovich et al., although the effects were not quantified by the authors (13). Dymeclin has common features with other Golgi proteins such as GRASP65 or ARF1. These three proteins are localized to the Golgi apparatus, they are myristoylated and they shuttle rapidly between a cytosolic pool and a Golgi pool. Dymeclin could therefore be involved in a GRASP like function and have a role in the structure and/or the function of the Golgi apparatus. GRASP65 has been involved in the formation of the mitotic spindle (20) but also in the fusion of the Golgi ribbons (21). In drosophila, the GRASP65 homologue is involved in non-conventional secretion (22) A related protein, GRASP55 was recently shown to be similarly involved in Golgi unlinking (23). Interestingly, unlinked Golgi cisternae are reminiscent of nocodazole-generated mini-stacks that cannot be recognized by Dymeclin. Structural defects were actually observed in patient cells which further argue for a role of Dymeclin in the regulation of Golgi apparatus organization.

Dymeclin could also have a role similar to the role played by ARF1 or Sar1 and be important for the formation of a complex of proteins (like COPI or COPII respectively) involved in a step of the intracellular transport $(24,25)$. This hypothesis could also explain the defects observed by electron microscopy in patient fibroblasts. In this context, it is interesting to note that a mutation in a component of the COPII coat component Sec23A leads to craniolenticulo-sutural dysplasia (26). In fibroblasts from these patients, the ER appears swollen and 
many tubular protrusions were observed (27). Sec23A is an ubiquitous protein, like Dymeclin, which is essential for intracellular transport but only affects some cell types.

Most of inherited diseases known to be associated with ER-Golgi anomalies involve cargo molecules that become unable to couple to the export machinery and then either undergo degradation or accumulate in the cell $(28,29,30)$. So far, few genetic disorders have been reported to involve central constituents of the ER-Golgi budding, presumably because their disruption is lethal. One of them, however, the X-linked skeletal disorder Spondyloepiphyseal dysplasia tarda (SEDT, MIM \#313400), is viable and associated with a loss-of-function of Sedlin, the functional counterpart of the yeast transport protein particle (TRAPP) Trs20p (31 , 32). Interestingly, TRAPP is a large cytosolic protein complex $(\sim 1,000 \mathrm{kDa})$ required for tethering ER-derived vesicles to Golgi membranes and for intra-Golgi traffic. In addition, SEDT is characterized by several features strikingly reminiscent of DMC $(3,33)$ : i) both diseases are chondrodysplasias with short-trunk dwarfism, ii) in both cases, the phenotype is not obvious at birth and appears progressively in childhood and iii) in both diseases, clinical features specifically include a broad chest with sternal protrusion and a flattened and humped appearance of the vertebral bodies. Although Dymeclin does not share any sequence homology with Sedlin, it is tempting to speculate that the two proteins may have a functional relationship in cartilage differentiation.

It will now be important to unravel Dymeclin's connection to other regulators of ER/Golgi dynamics and function to understand better the role that this protein plays in the development of the DMC/SMCdysplasias.

\section{Materials and Methods}

\section{Multiple-tissue expression array and Northern blot}

Pre-made human multiple-tissue expression array (MTE; ref 7776-1 Clontech Laboratories) and Northern blot containing $20 \mu \mathrm{g}$ of total RNA extracted from human primary chondrocytes, calvarial osteoblasts, immortalized chondrocytes, SaOs2, HeLa and murine ES cells were hybridized overnight at $42^{\circ} \mathrm{C}$ with either a $0.85 \mathrm{~kb}$ cDNA fragment corresponding to the 5'-end of DYM (probe A) or a $0.5 \mathrm{~kb}$ cDNA fragment selected in the 3'-end of Dym (probe B), labelled and purified as previously described (2). Primers used to generate probe A were selected in exons 2 and 9 (2). Primers used to generate probe B were selected in exon 10 (10Sintra: 5'-CTCCTCTTGTATACCTTGCT-3') and exon 14 (8ASintra: 5'- 
AGGAACATCATTAGAACTCAG-3'). Blots were washed three times at $42{ }^{\circ} \mathrm{C}$ with $2 \times \mathrm{SSC}: 0.1 \%$ SDS for 15 minutes and once under more stringent conditions, at $65{ }^{\circ} \mathrm{C}$ with $0.1 \times$ SSC $: 0.1 \%$ SDS for 10 minutes and further exposed overnight to Kodak X-Omat films with an intensifying screen at $-80{ }^{\circ} \mathrm{C}$.

\section{In situ hybridization}

Human embryos and foetal tissues were collected from legally terminated pregnancies in agreement with the French law and Ethics Committee recommendations. Tissues were fixed in $4 \%$ paraformaldehyde, embedded in paraffin blocks and sectioned $(5 \mu \mathrm{m})$. Primers located in exon 7 (7F: 5'-AAGAAGTTTTGCGACAGAGC-3') and exon 9 (9R:5'GGCCAGAGGGGAAGAAAG-3') of DYM cDNA were selected for PCR amplification of a 315 bp product. A $\mathrm{T} 7$ promoter sequence extension (5'TAATACGACTCACTATAGGGAGA-3') was added at the 5' end of each primer. T7-7F/9R and 7F/T7-9R sets allowed amplification of sense and antisense templates. Ribobropes were labelled using T7 polymerase in the presence of $\alpha\left[{ }^{35} \mathrm{~S}\right] \mathrm{UTP}(1200 \mathrm{Ci} / \mathrm{mmol}$; NEN) and purified on Sephadex G50 columns. Hybridization and post-hybridization washes were carried out according to standard protocols (34). Slides were dehydrated, exposed to BIOMAX MR X-ray films (Amersham) for 3 days, dipped in Kodak NTB2 emulsion for 3 weeks at $+4{ }^{\circ} \mathrm{C}$, then developed and counterstained in toluidine blue, coverslipped with Eukitt, and analysed under dark and bright field illumination. No hybridization signal was detected with the $\alpha[35 \mathrm{~S}]$-labelled sense probe.

\section{Plasmids and site-directed mutagenesis}

The coding region of human DYM cDNA (FLJ90130, DDBJ/EMBL/Genbank accession number AK074611) was purchased from the Biological Resource Center, Japan (NBRC) as an insert cloned into the pME18SFL3 plasmid. However, the clone differed by two nucleotides from the human sequence we previously identified (2) changing a glutamate into a lysine at codon 66 and a leucine into a proline at codon 249. These two mismatches were corrected using the QuickChange XL site directed in vitro mutagenesis kit, following the manufacturer's instructions (Stratagene). The cDNA of DYM was amplified by PCR and subcloned in the pEGFP-N2 vector (Clontech) between XhoI and BamHI. The QuickChange XL site directed in vitro mutagenesis kit was used to generate the R204X, Q483X, K616X, E87K and N469Y mutations. Primers designed to mutate the myristoylation site of Dymeclin were as follow: G2Afor, 5'-AGCTTGAAGATGGCATCGAATAGCAGC-3', G2Arev, 5'- 
GCTGCTATTCGATGCCATCTTCAAGCT-3'. In FRAP analyses, we used pEGFP ARF1 and pEGFP GRASP65 (kindly provided by F. Barr). All constructs were verified by direct sequencing using the ABI PRISM BigDye Terminator Cycle Sequencing Reaction Kit on an automatic ABI3100 capillary sequencer (Applied Biosystems).

\section{Cell culture and transfection}

HeLa cells were grown in Dulbecco's modified Eagle's medium (DMEM, Gibco) containing $4.5 \mathrm{~g} / \mathrm{l}$ glucose supplemented with $10 \%$ fetal calf serum, $5 \mathrm{mM}$ glutamine, $5 \mathrm{mM}$ sodium pyruvate at $37{ }^{\circ} \mathrm{C}$ in a $5 \% \mathrm{CO} 2$ humidified incubator. For transfections, cells were plated on coverslips the day before transfection, and were transfected using lipofectamin 2000 (Invitrogen). The cells were fixed with either $100 \%$ methanol at $-20^{\circ} \mathrm{C}$ for 5 minutes or $3 \%$ PFA at room temperature for 15 minutes, washed with PBS, incubated with PBS-0,1M $\mathrm{NH} 4 \mathrm{Cl}$ for 5 minutes, washed again with PBS and permeabilized with $0,1 \%$ Triton X100 for 5 minutes.

\section{Immunoprecipitation}

Immunoprecipitations were carried out by using extracts prepared from HeLa cells overexpressing Dym-GFP with the Protein G-agarose Immunoprecipitation kit from Roche. Briefly, cell lysates were first incubated on a rocking platform 5 hours at $4{ }^{\circ} \mathrm{C}$ with $50 \mu \mathrm{l}$ of the homogeneous G-suspension and centrifuged 20 seconds at $12000 \mathrm{~g}$. The supernatant was then incubated with 2-4 $\mu \mathrm{g}$ of mouse monoclonal anti-GFP antibody (Roche) overnight at 4 ${ }^{\circ} \mathrm{C}$ and another $50 \mu \mathrm{l}$ of the homogeneous G-suspension was added for 5 hours. After several washes of the complexes, the immunoprecipitated proteins were separated by SDS-PAGE and electroblotted on PVDF membranes (Immobilon, Millipore). The membranes were preincubated for 1 hour at $4{ }^{\circ} \mathrm{C}$ in TBS (20 mM Tris- $\mathrm{HCl}$ ph7.4, $150 \mathrm{mM} \mathrm{NaCl}$ ) containing $5 \%$ skim milk. The blots were then incubated overnight at $4{ }^{\circ} \mathrm{C}$ with either anti-GFP (control) or anti-Dym antibodies both at dilutions of 1/1000. After membrane washing, a second antibody coupled to peroxidase was added. Proteins were visualized with the ECL detection kit (Amersham).

\section{Permeabilization assays and drugs}

For permeabilization assays, cells grown on a glass bottom chamber (Iwaki) were treated directly during imaging with $60 \mu \mathrm{M}$ digitonin for 1 minute. For Nocodazole treatment, cells 


\section{Live imaging}

For FRAP analyses with Dym-GFP, ARF1-GFP and GRASP65-GFP. HeLa cells were maintained in culture medium in glass bottom chambers (Iwaki) and imaged on a Leica DMIRE2 with a Roper Cascade II Camera, Polychrome V and a 100x NA 1.35 oil oblective, twenty-four hours after transfection. Images were collected before bleaching of the Golgi and every 50 milliseconds after photobleaching. Images were processed using Metamorph software. After correction of the photobleaching due to acquisition, the background was subtracted. The intensity of fluorescence was then normalized and the half recovery was quantified. For nocodazole treated cells the images were acquired on a spinning disk microscope. The Spinning disk microscope is based on a CSU-22 Yokogawa head mounted on an inverted TE-2000E Nikon microscope equipped with a motorized Märzhäuser XY Stage. Images are acquired through a 60x 1.4NA Plan-Apo objective with a Photometrics Coolsnap HQ2 CCD camera. Optical sectioning is achieved using a PI Pifoc piezo z-drive mounted between the microscope turret and the objective. A Roper/Errol laser lounge is equipped with $488 \mathrm{~nm}$ and $514 \mathrm{~nm}$ laser diodes, delivering $50 \mathrm{~mW}$ each, coupled to the spinning disk head through a single fiber. Multi-dimensional acquisitions are performed in streaming mode using Metamorph 7.1.7 software. Images were collected before bleaching of the Golgi and every 400 milliseconds after photobleaching for Dym-GFP and mCherryGM130. The data shown in the movies where obtained using ND-SAFIR (N-Dimensional Structure Adaptive Filtering for Image Restoration) (C) INRIA/INRA 2007 as previously described $(35,36)$. 


\section{Immunoelectron microscopy}

Briefly, cells were fixed with $2 \%$ paraformaldehyde, $0.125 \%$ glutaraldehyde in culture medium for 30 minutes at $37{ }^{\circ} \mathrm{C}$. This medium was removed and replaced by PFA $2 \%+$ $0,125 \%$ glutaraldehyde in phosphate buffer $\mathrm{pH} 7,4$ for 2 hours at $37{ }^{\circ} \mathrm{C}$. This fixative was replaced by PFA $2 \%$ in phosphate buffer $\mathrm{pH}$ 7,4. Cells were then processed for ultracryomicrotomy as previously described (37). Ultrathin cryosections were prepared with an ultracryomicrotome Ultracut FCS (Leica, Vienna, Austria) and immunogold labeled with the indicated primary antibodies and using protein A conjugated to $10 \mathrm{~nm}$ gold (Cell Microscopy Center, AZU, Utrecht, The Netherlands). Sections were analyzed under a Philips CM120 electron microscope, and digital acquisitions were made with a numeric camera Keen View (Soft Imaging Systems, Münster, Germany).

\section{Funding}

This work was supported by the Institut National pour la Santé et la Recherche Médicale (INSERM), the Centre National de la Recherche Scientifique (CNRS), the Institut Curie, the Université Paris 7 and the Agence Nationale pour la recherche (ANR).

\section{Acknowledgments}

The authors whish to thank Cécile Martel for strong support during preparation of the manuscript, Florence Jollivet and Noman Kadhom for assistance in cell culture and immunoassays, Jérôme Boulanger and Vincent Fraisier for assistance in data acquisition and treatment, Géraldine Goudefroye and Férechté Encha-Razavi for assistance in situ hybridization. The authors also thank Michel Vekemans for providing the invaluable support for working on human embryos, Valérie Doye for providing the cell line stably expressing mCherry-Histone and Angela M. Kaindl for reading and fruitful comments on the manuscript. 


\section{References}

1. Cohn, D.H., Ehtesham, N., Krakow, D., Unger, S., Shanske, A., Reinker, K., Powell, B.R. and Rimoin, D.L. (2003) Mental retardation and abnormal skeletal development (Dyggve-Melchior-Clausen dysplasia) due to mutations in a novel, evolutionarily conserved gene. Am J Hum Genet, 72, 419-28.

2. El Ghouzzi, V., Dagoneau, N., Kinning, E., Thauvin-Robinet, C., Chemaitilly, W., Prost-Squarcioni, C., Al-Gazali, L.I., Verloes, A., Le Merrer, M., Munnich, A. et al. (2003) Mutations in a novel gene Dymeclin (FLJ20071) are responsible for DyggveMelchior-Clausen syndrome. Hum Mol Genet, 12, 357-64.

3. Paupe, V., Gilbert, T., Le Merrer, M., Munnich, A., Cormier-Daire, V. and El Ghouzzi, V. (2004) Recent advances in Dyggve-Melchior-Clausen syndrome. Mol Genet Metab, 83, 51-9.

4. Kinning, E., Tufarelli, C., Winship, W.S., Aldred, M.A. and Trembath, R.C. (2005) Genomic duplication in Dyggve Melchior Clausen syndrome, a novel mutation mechanism in an autosomal recessive disorder. J Med Genet, 42, e70.

5. Engfeldt, B., Bui, T.H., Eklof, O., Hjerpe, A., Reinholt, F.P., Ritzen, E.M. and Wikstrom, B. (1983) Dyggve-Melchior-Clausen dysplasia. Morphological and biochemical findings in cartilage growth zones. Acta Paediatr Scand, 72, 269-74.

6. Nakamura, K., Kurokawa, T., Nagano, A., Nakamura, S., Taniguchi, K. and Hamazaki, M. (1997) Dyggve-Melchior-Clausen syndrome without mental retardation (Smith-McCort dysplasia): morphological findings in the growth plate of the iliac crest. Am J Med Genet, 72, 11-7.

7. Kinning E., F.J.A., El Ghouzzi V., Cormier-Daire V., Trembath R.C. (2003) Insights as to the function of Dymeclin, the protein product of the Dyggve-Melchior-Clausen syndrome (DMC) gene. European Human Genetics Conference. Birmingham, UK, Vol. 11suppl, p. P556.

8. Farazi, T., Leichman, J., Harris, T., Cahoon, M. and Hedstrom, L. (1997) Isolation and characterization of mycophenolic acid-resistant mutants of inosine-5'-monophosphate dehydrogenase. J Biol Chem, 272, 961-5.

9. Lorenz, H., Hailey, D.W., Wunder, C. and Lippincott-Schwartz, J. (2006) The fluorescence protease protection (FPP) assay to determine protein localization and membrane topology. Nature protocols, 1, 276-9.

10. Vasudevan, C., Han, W., Tan, Y., Nie, Y., Li, D., Shome, K., Watkins, S.C., Levitan, E.S. and Romero, G. (1998) The distribution and translocation of the G protein ADPribosylation factor 1 in live cells is determined by its GTPase activity. Journal of cell science, 111 ( Pt 9), 1277-85.

11. Presley, J.F., Ward, T.H., Pfeifer, A.C., Siggia, E.D., Phair, R.D. and LippincottSchwartz, J. (2002) Dissection of COPI and Arf1 dynamics in vivo and role in Golgi membrane transport. Nature, 417, 187-93.

12. Nizak, C., Martin-Lluesma, S., Moutel, S., Roux, A., Kreis, T.E., Goud, B. and Perez, F. (2003) Recombinant antibodies against subcellular fractions used to track endogenous Golgi protein dynamics in vivo. Traffic (Copenhagen, Denmark), 4, 73953.

13. Osipovich, A.B., Jennings, J.L., Lin, Q., Link, A.J. and Ruley, H.E. (2008) DyggveMelchior-Clausen syndrome: Chondrodysplasia resulting from defects in intracellular vesicle traffic. Proc Natl Acad Sci U S A. 
14. Bertoni-Freddari, C., Fattoretti, P., Casoli, T., Di Stefano, G., Solazzi, M., Gracciotti, N. and Pompei, P. (2001) Mapping of mitochondrial metabolic competence by cytochrome oxidase and succinic dehydrogenase cytochemistry. $J$ Histochem Cytochem, 49, 1191-2.

15. Snyder, C.M., Mardones, G.A., Ladinsky, M.S. and Howell, K.E. (2006) GMx33 associates with the trans-Golgi matrix in a dynamic manner and sorts within tubules exiting the Golgi. Molecular biology of the cell, 17, 511-24.

16. Beck, M., Lucke, R. and Kresse, H. (1984) Dyggve-Melchior-Clausen syndrome: normal degradation of proteodermatan sulfate, proteokeratan sulfate and heparan sulfate. Clin Chim Acta, 141, 7-15.

17. Naffah, J. (1976) The Dyggve-Melchior-Clausen syndrome. Am J Hum Genet, 28, 607-14.

18. Ristow, M., Mulder, H., Pomplun, D., Schulz, T.J., Muller-Schmehl, K., Krause, A., Fex, M., Puccio, H., Muller, J., Isken, F. et al. (2003) Frataxin deficiency in pancreatic islets causes diabetes due to loss of beta cell mass. J Clin Invest, 112, 527-34.

19. Toledo, S.P., Saldanha, P.H., Lamego, C., Mourao, P.A., Dietrich, C.P. and Mattar, E. (1979) Dyggve-Melchior-Clausen syndrome: genetic studies and report of affected sibs. Am J Med Genet, 4, 255-61.

20. Sutterlin, C., Polishchuk, R., Pecot, M. and Malhotra, V. (2005) The Golgi-associated protein GRASP65 regulates spindle dynamics and is essential for cell division. Molecular biology of the cell, 16, 3211-22.

21. Puthenveedu, M.A., Bachert, C., Puri, S., Lanni, F. and Linstedt, A.D. (2006) GM130 and GRASP65-dependent lateral cisternal fusion allows uniform Golgi-enzyme distribution. Nature cell biology, 8, 238-48.

22. Schotman, H., Karhinen, L. and Rabouille, C. (2008) dGRASP-mediated noncanonical integrin secretion is required for Drosophila epithelial remodeling. Dev Cell, 14, 17182.

23. Feinstein, T.N. and Linstedt, A.D. (2008) GRASP55 regulates Golgi ribbon formation. Mol Biol Cell, 19, 2696-707.

24. Kirby, D.M., Salemi, R., Sugiana, C., Ohtake, A., Parry, L., Bell, K.M., Kirk, E.P., Boneh, A., Taylor, R.W., Dahl, H.H. et al. (2004) NDUFS6 mutations are a novel cause of lethal neonatal mitochondrial complex I deficiency. J Clin Invest, 114, 83745.

25. Sato, K. (2004) COPII coat assembly and selective export from the endoplasmic reticulum. Journal of biochemistry, 136, 755-60.

26. Boyadjiev, S.A., Fromme, J.C., Ben, J., Chong, S.S., Nauta, C., Hur, D.J., Zhang, G., Hamamoto, S., Schekman, R., Ravazzola, M. et al. (2006) Cranio-lenticulo-sutural dysplasia is caused by a SEC23A mutation leading to abnormal endoplasmicreticulum-to-Golgi trafficking. Nature genetics, 38, 1192-7.

27. Fromme, J.C., Ravazzola, M., Hamamoto, S., Al-Balwi, M., Eyaid, W., Boyadjiev, S.A., Cosson, P., Schekman, R. and Orci, L. (2007) The genetic basis of a craniofacial disease provides insight into COPII coat assembly. Developmental cell, 13, 623-34.

28. Aridor, M. and Balch, W.E. (1999) Integration of endoplasmic reticulum signaling in health and disease. Nat Med, 5, 745-51.

29. Kim, P.S. and Arvan, P. (1998) Endocrinopathies in the family of endoplasmic reticulum (ER) storage diseases: disorders of protein trafficking and the role of ER molecular chaperones. Endocr Rev, 19, 173-202.

30. Shields, D. and Arvan, P. (1999) Disease models provide insights into post-golgi protein trafficking, localization and processing. Curr Opin Cell Biol, 11, 489-94. 
31. Gecz, J., Shaw, M.A., Bellon, J.R. and de Barros Lopes, M. (2003) Human wild-type SEDL protein functionally complements yeast Trs20p but some naturally occurring SEDL mutants do not. Gene, 320, 137-44.

32. Gedeon, A.K., Colley, A., Jamieson, R., Thompson, E.M., Rogers, J., Sillence, D., Tiller, G.E., Mulley, J.C. and Gecz, J. (1999) Identification of the gene (SEDL) causing X-linked spondyloepiphyseal dysplasia tarda. Nature genetics, 22, 400-4.

33. Savarirayan, R., Thompson, E. and Gecz, J. (2003) Spondyloepiphyseal dysplasia tarda (SEDL, MIM \#313400). Eur J Hum Genet, 11, 639-42.

34. Wilkinson, D. (1992) Wilkinson, D. (1992). In situ hybridization: A practical approach. Oxford University Press, Oxford.

35. Boulanger, J., Kervrann, C. and Bouthemy, P. (2007) Space-time adaptation for patchbased image sequence restoration. IEEE transactions on pattern analysis and machine intelligence, 29, 1096-102.

36. Boulanger, J., Sibarita, J.-B., Kervrann, C. and Bouthemy, P. (2008) Non-parametric regression for patch-based fluoresence microscopy image sequence denoising. Proc. IEEE Int. Symp. on Biological Imaging (ISBI'08), Apr 2008.

37. Raposo, G., Tenza, D., Mecheri, S., Peronet, R., Bonnerot, C. and Desaymard, C. (1997) Accumulation of major histocompatibility complex class II molecules in mast cell secretory granules and their release upon degranulation. Molecular biology of the cell, 8, 2631-45. 


\section{Legends to figures}

\section{Figure 1: Expression of Dym throughout human development}

A: Tissue distribution of human Dym transcripts. MTE array was probed with an $850 \mathrm{bp}$ human Dym radiolabeled probe (probe A) as described in experimental procedures and spots corresponding to the most intense expressions (up to 100 arbitrary units) were quantified using Sigmagel (Jandel Scientific, v1.0). The identity of each cDNA dot is as follows: A1, whole brain, A2, cerebellum left, A3, substantia nigra, A4, heart, A5, esophagus, A6, colon transverse, A7, kidney, A8, lung, A9, liver, A10, leukaemia HL-60, A11, fetal brain, A12, yeast total RNA, B1, cerebral cortex, B2, cerebellum right, B3, nucleus accumbens, B4, aorta, B5, stomach, B6, colon desending, B7, skeletal muscle, B8, placenta, B9, pancreas, B10, HeLa S3, B11, fetal heart, B12, yeast tRNA, C1 frontal lobe, C2, corpus callosum, C3, thalamus, C4, atrium left, C5, duodenum, C6, rectum, C7, spleen, C8, bladder, C9, adrenal gland, C10, leukaemia K-562, C11, fetal kidney, C12, E.coli rRNA, D1, parietal lobe, D2, amygdala, D3, pituary gland, D4, atrium right, D5, jejunum, D7, thymus, D8, uterus, D9, thyroid gland, D10, leukaemia MOLT-4, D11, fetal liver, D12, E.coli DNA, E1, occipital lobe, E2, caudate nucleus, E3, spinal cord, E4, ventricle left, E5, ileum, E7, peripheral blood leukocytes, E8, prostate, E9, salivary gland, E10, Burkitt's lymphoma, Raji, E11, fetal spleen, E12, poly r(A), F1, temporal lobe, F2, hippocampus, F4, ventricle right, F5, ileocecum, F7, lymph node, F8, testis, F9,mammary gland, F10, Burkitt's lymphoma, Daudi, F11, fetal thymus, F12, human Cot-1 DNA, G1, paracentral gyrus of cerebral cortex, G2, medulla oblongata, G4, interventricular septum, G5, appendix, G7, bone marrow, G8, ovary, G10, colorectal adenocarcinoma SW480, G11, fetal lung, G12, human DNA 100ng, H1, pons, H2, putamen, H4, apex of the heart, H5, colon ascending, H7, trachea, H10, lung carcinoma, A549, H12, human DNA 500ng. No sample was spotted in F3-H3, D6-H6, H8, H9, H11 and G9. C, Northern blot analysis was performed using probe A, which recognizes two Dym variants $(3.1 \mathrm{~kb}$ and $5.6 \mathrm{~kb})$. The amount in each lane is normalized with RNA $18 \mathrm{~s}$.

\section{B: In situ hybridization analysis of Dym transcripts during human embryo-foetal} development. Hematoxylin/eosin stained sections under bright field illumination (A, D, F, H, $\mathrm{J}, \mathrm{L}, \mathrm{N}, \mathrm{P}, \mathrm{R}, \mathrm{T}, \mathrm{V})$ and adjacent Dym-hybridized sections under dark field illumination (B, C, E, G, I, K, M, O, Q, S, U, W). A-C, Sagittal sections of a CS19 embryo (x10); as a negative control of hybridization, the sense Dym probe was used (C). D-E, Magnification of the lung 
$(\mathrm{Lu}, \mathrm{x} 25, \mathrm{D})$ and the intestinal epithelium $(\mathrm{x} 32, \mathrm{~F}, \mathrm{G})$ corresponding to the black squares in A; White arrows point to elective signal seen in mesenchymal condensations (E). H-K, Transversal sections of the cerebellum from a 17-week foetus $(x 10, H, I)$ and $x 32$ magnification showing Dym expression in the external granule layer (J, K). L-M, Dym expression in the hippocampus from a 17 -week foetus (x8). N-O, Dym expression in the neocortical plate and in the corresponding germinative zone from a 17-week foetus (x12). P$\mathrm{S}$, Dym expression in the cerebellum from a 22-week foetus (x8) and higher magnification showing Dym expression in the external granule layer, the Purkinje neurons and the internal granule layer (x40, R and S). T-U, Dym expression in the hippocampus from a 22-week foetus (x40). V-W, Dym expression in the neocortical plate and in the corresponding germinative zone from a 22 -week foetus (x12).

Figure 2: Immuno-detection of endogeneous Dymeclin in HeLa cells. A: Intracellular localization of endogeneous Dymeclin in HeLa cells. HeLa cells (Top panel) were fixed and stained with the anti-Dym antibody at dilution 1/400. The Golgi was labeled with GM130 (red). Hela cells transfected with Dym(N469Y)-GFP (Bottom panel) were fixed and stained for Dymeclin (red) and GM130 (pink). B: Immunoprecipitation of Dym-GFP. Lysates from HeLa cells over-expression Dym-GFP (lane 1) were immunoprecipitated with either the antiGFP antibody (lane 2) or the anti-Dym antibody (lane 3).

Figure 3: Intracellular localization of Dym-GFP in HeLa cells. A: Reconstruction from 3D images of HeLa cells transfected with Dym-GFP and stained with antibodies against Giantin (in red, top line) and GalT (in blue, top line) or TGN46 (in red, bottom line) and GM130 (in blue, bottom line). Dym-GFP partially co-localized with the different Golgi markers and was also found as a soluble pool. B: Immunogold labeling on cryosections of Dym-GFP transfected HeLa cells visualized by electron microscopy confirmed that the protein is localized on the Golgi apparatus and in the cytosol.

Figure 4: Myristoylation of Dymeclin in vitro and intracellular localization of the G2A mutant in HeLa cells. A: Dymeclin was produced in vitro in the presence of either ${ }^{35} \mathrm{~S}$ methionine (left panel) or ${ }^{3} \mathrm{H}$-myristate (right panel). Wild-type Dymeclin (Dym WT) can be myristoylated in vitro and the mutation of the second Glycine into an Alanine (Dym G2A) prevents the myristoylation. B: Hela cells were transfected with Dym-GFP or Dym-G2A-GFP (green) and stained for GM130 (red). 
Figure 5: In vivo permeabilization with Digitonin. Hela cells stably expressing mCherryHistone were transfected with either Dym-GFP, ARF1-GFP or GRASP65-GFP. 3D images were acquired on a spinning disk microscope before treatment and one minute after treatment with $60 \mu \mathrm{M}$ Digitonin. In permeabilized cells Dym-GFP has completely disappeared from the Golgi and the cytosol whereas ARF1-GFP is dimly visible on the Golgi apparatus and GRASP65-GFP is still present.

Figure 6: Quantification of Dym-GFP dynamics. Hela cells were transfected with either Dym-GFP, Arf1-GFP or GRASP65-GFP and photobleaching experiments were performed 24 hours after. A. The Golgi apparatus of one cell (outlined in white in the movie) was bleached after 10 seconds and images were then acquired every 100 mseconds for 1 minute (see mov. 1). After 13,5 seconds the fluorescence of Dym-GFP has totally recovered. From these experiments we could quantify the Golgi fraction of the three proteins. The percentage of protein on the Golgi is represented in B. 16,5 $\pm 4 \%$ of Arf1-GFP, 13,6 $\pm 3,9 \%$ of Dymeclin and $33,2 \pm 10,8 \%$ of GRASP65-GFP are on the Golgi. The normalized intensity of fluorescence for the three proteins was plotted on the same graph. The mean value is indicated in black and the SD is indicated in grey. The half time of recovery was calculated from these data as shown in C. GRASP65-GFP recovered more slowly with a half time of $12,4 \pm 4,5$ seconds, the recovery of Arf1-GFP was faster with a half time of 7,1 $\pm 2,6$ seconds and DymGFP was even faster with a half time of recovery of $2,8 \pm 0,9$ seconds.

Figure 7: Intracellular localization and dynamics of Dym-GFP upon nocodazole treatment. A: HeLa cells transfected with Dym-GFP were fixed 24 hours after transfection and the Golgi was labeled with GM130 (red) and Giantin (blue). In non treated cells (top line) the three markers co-localized whereas after $1 \mathrm{~h} 30$ at $4^{\circ} \mathrm{C}$ and $1 \mathrm{~h} 30$ at $37^{\circ} \mathrm{C}$ with $10 \mu \mathrm{M}$ nocodazole (bottom line) GM130 was present on the mini stacks dispersed in the cell and Giantin and Dym-GFP were co-localized on the "Old Golgi" in the center of the cell. B: FRAP experiments were performed on cells co-transfected with mCherry-GM130 and DymGFP (see sup. Movie 2). The first line shows the Dym-GFP before (-1"), immediately after $(0 ")$ or 9 seconds after (9") the photobleaching (indicated by the white arrows). The second line shows the mCherry-GM130 and the last line corresponds to the overlay of Dym-GFP in green and mCherry-GM130 in red. The insert shows the upper bleach region with a three 
times magnification. Dym-GFP is present on the "Old Golgi" but not on the mini stacks that are only positive for GM130. After photobleaching of the "Old Golgi" both Dym-GFP fluorescence and mCherry-GM130 fluorescence are decreased. The recovery of Dym-GFP is complete within 9 seconds whereas mCherry-GM130 has not recovered.

Figure 8: Mis-localization and degradation of Dymeclin bearing DMC mutations. A: HeLa cells transfected with wild-type (WT) or mutant GFP-Dym (K616X, Q483X, R204X, N469Y, E87K) were fixed 24 hours after transfection and the Golgi was labeled with GM130 (red). B: HeLa cells transfected with GFP-Dym(R204X) or GFP-Dym(N469Y) were fixed 24 hours after transfection and labeled with an anti-ubiquitin antibody (red). Ubiquitin was found co-localized with mutant GFP-Dym aggregates.

Figure 9: Schematic representation of Dymeclin dynamic localization. A: This model proposes that, in the non treated cells, Dymeclin (in green) and Arf1 (in red) are present as a soluble pool and a Golgi pool and shuttle rapidly between the two (green and red arrows). B: In nocodazole treated cells Arf1 is localized on the "Old Golgi" and on the newly formed mini stacks whereas Dymeclin is present only on the "Old Golgi" and not on the mini stacks. Both proteins exchange rapidly.

\section{Movies captions (Quick Time format)}

\section{Movie 1: DymFRAP.mov}

FRAP analysis of Dym-GFP in live transfected HeLa cells showing the rapid replenishment of Dym-GFP fluorescence in the Golgi apparatus after photobleaching. For details, see Dimitrov et al, Figure 6.

\section{Movie 2: Dym-GM130_Nz-FRAP.mov}

FRAP analysis of Dym-GFP and mCherry-GM130 in live transfected HeLa cells, incubated at $4^{\circ} \mathrm{C}$ for $1 \mathrm{~h} 30$ and treated with $10 \mu \mathrm{M}$ nocodazole at $37^{\circ} \mathrm{C}$, showing no replenishment of mCherry-GM130 and rapid replenishment of Dym-GFP fluorescence in the "Old Golgi" after photobleaching. For details, see Dimitrov et al, Figure 7. 
A
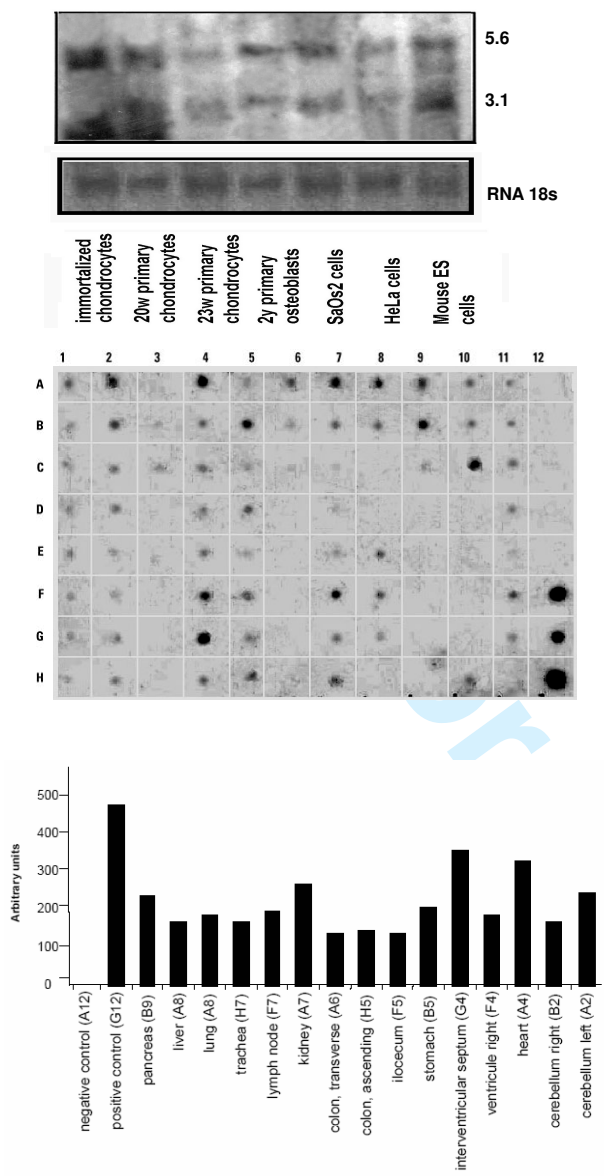

B

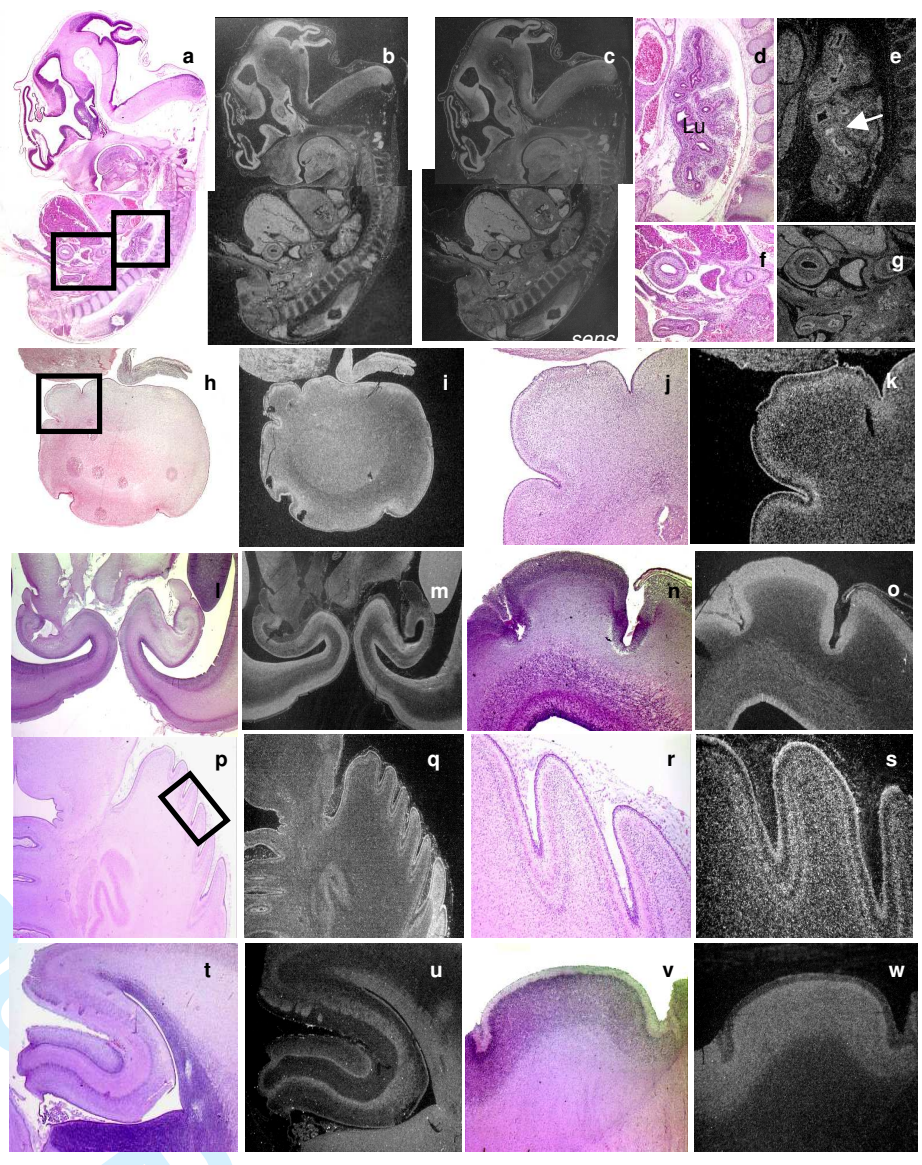

Figure 1, Dimitrov et al 

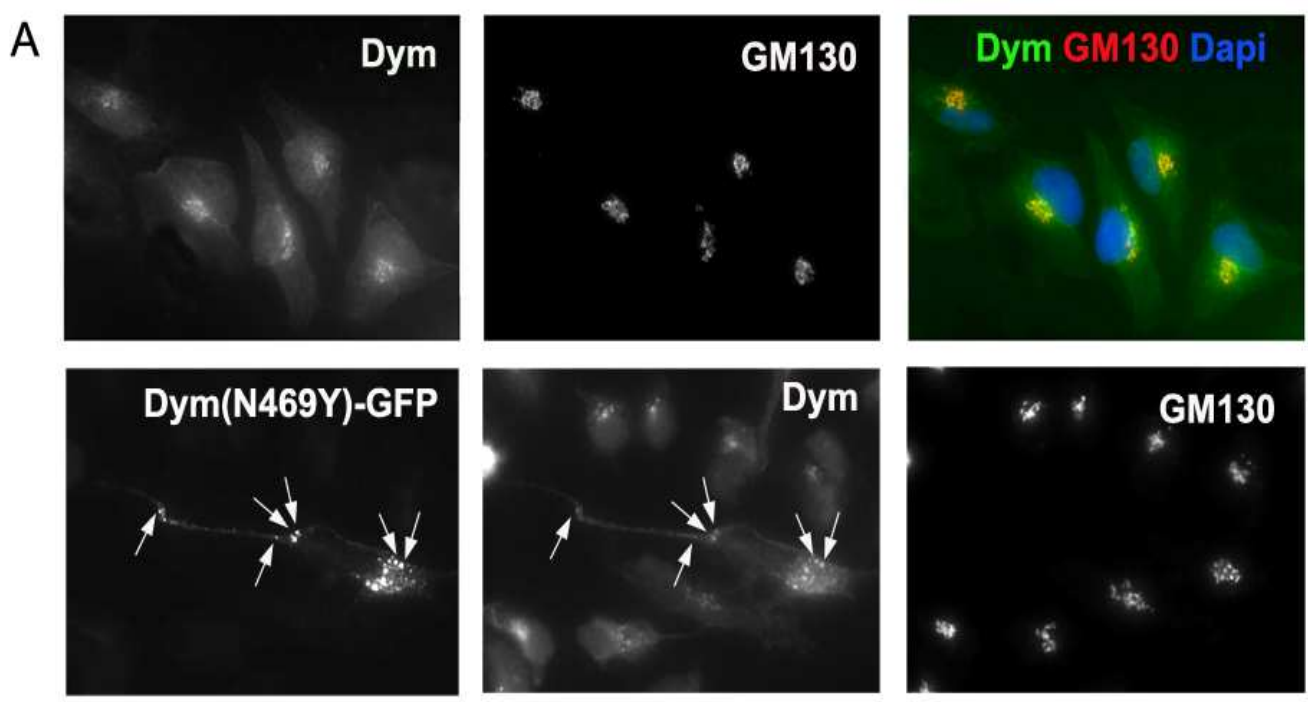
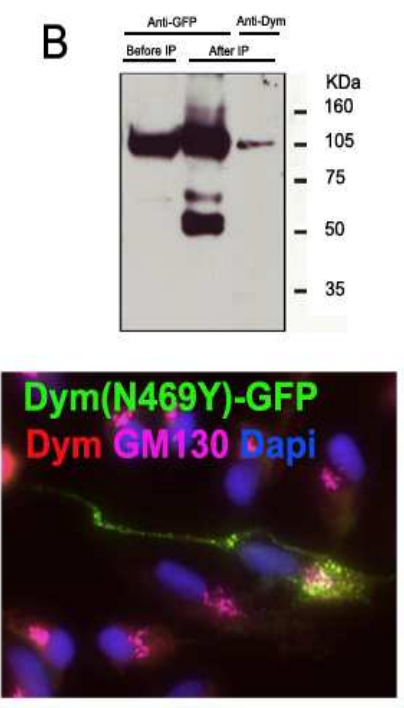

Figure 2, Dimitrov et al 


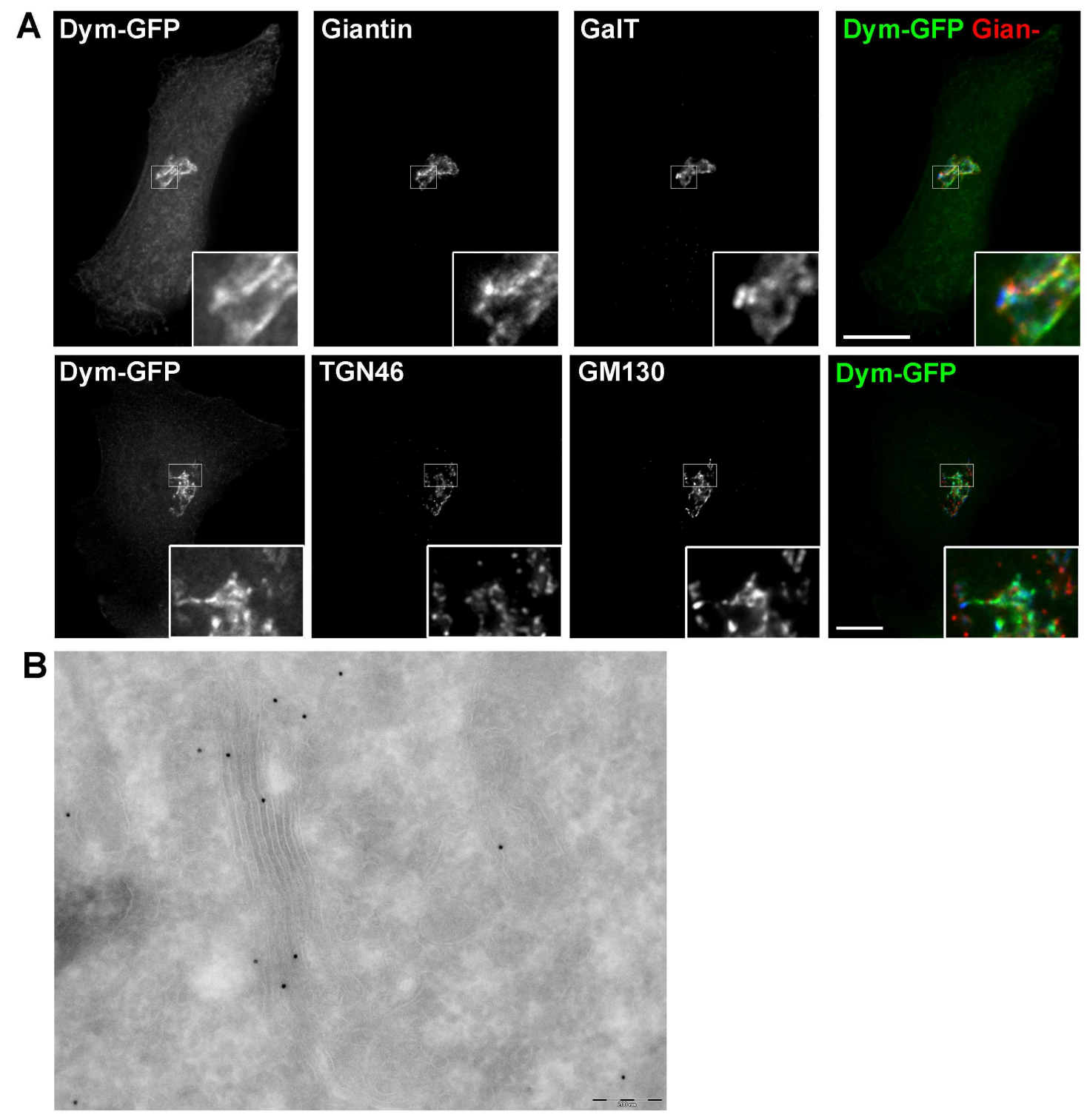

Figure 3, Dimitrov et al 

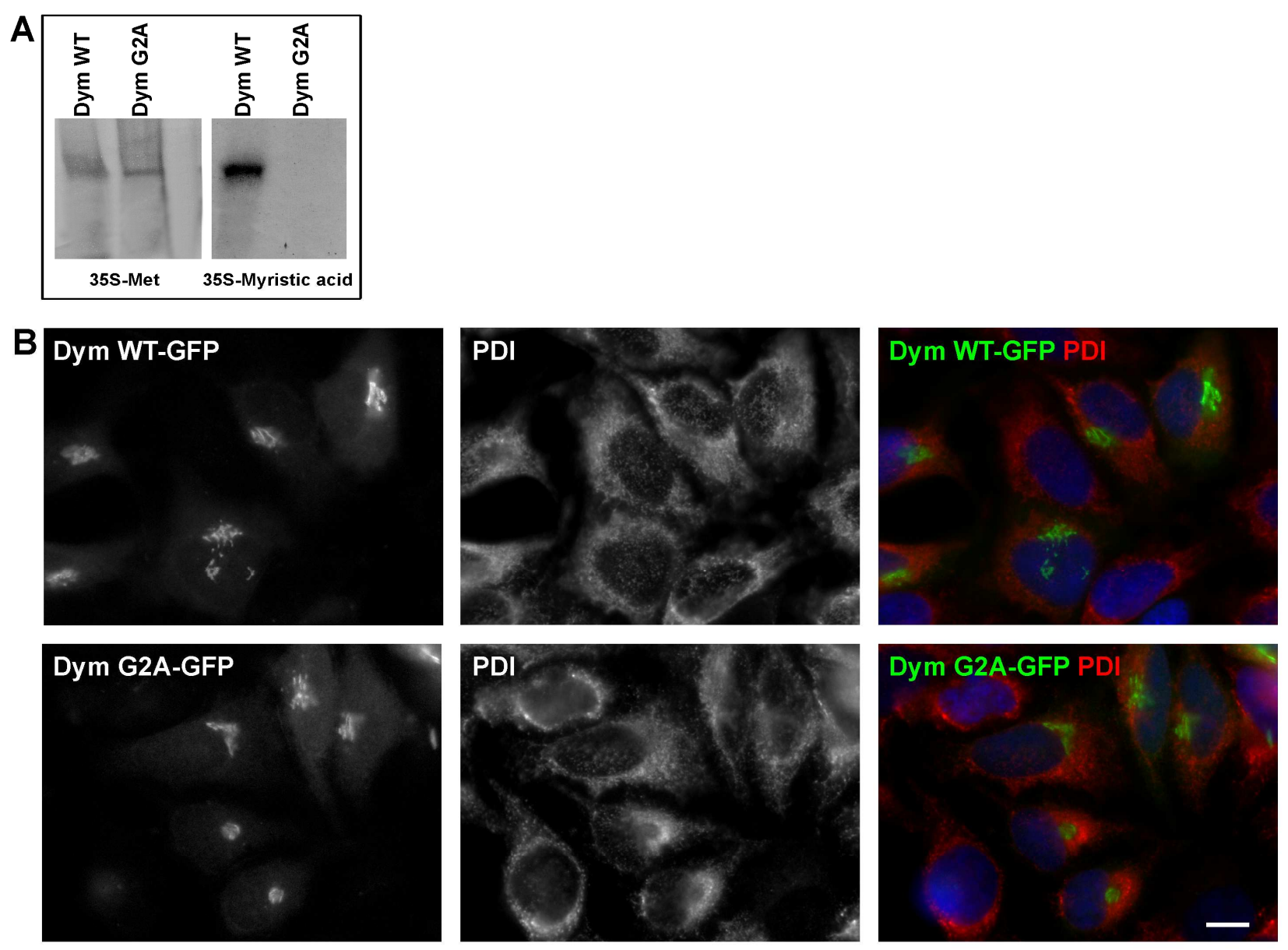

Figure 4, Dimitrov et al 


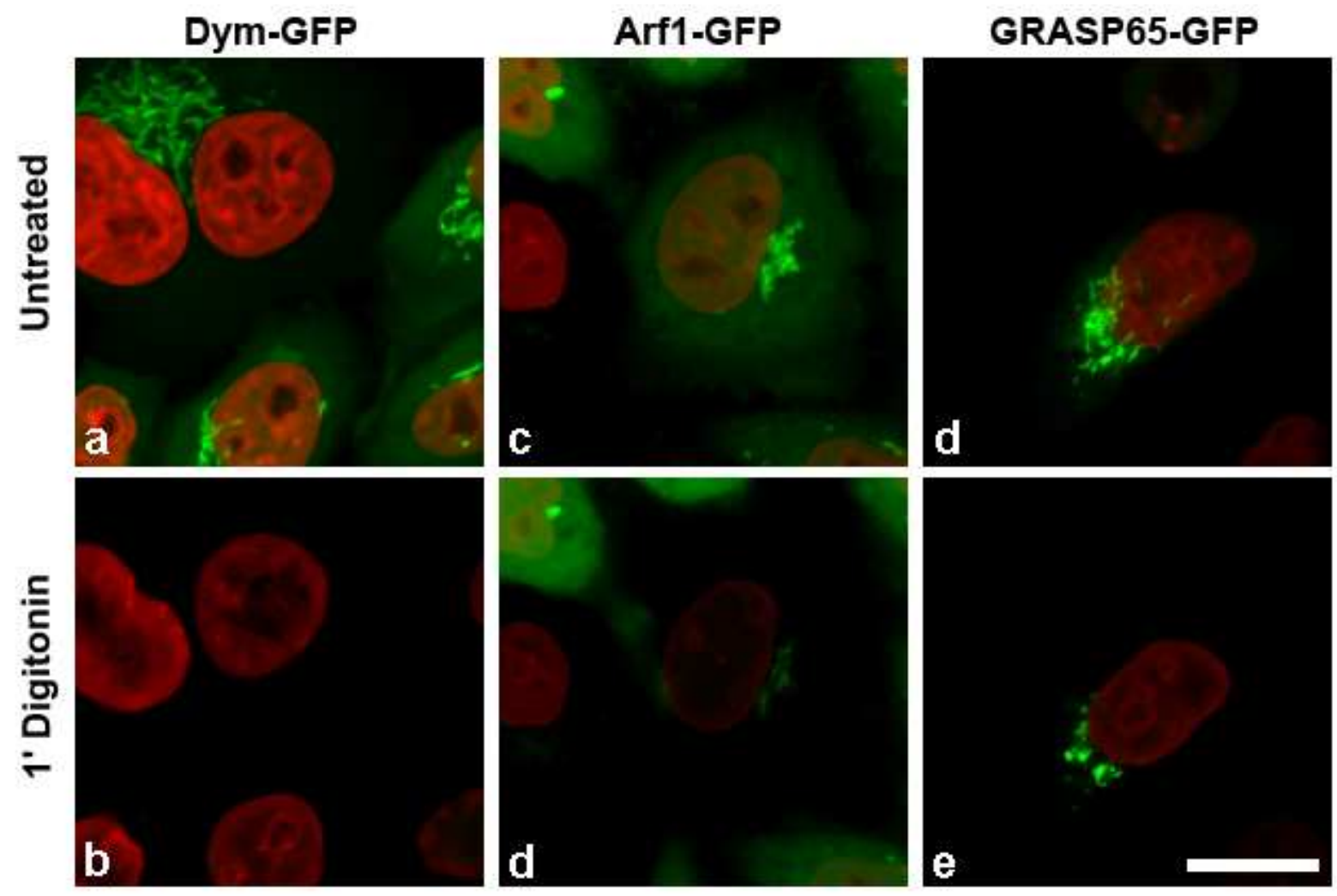

Figure 5, Dimitrov et al 

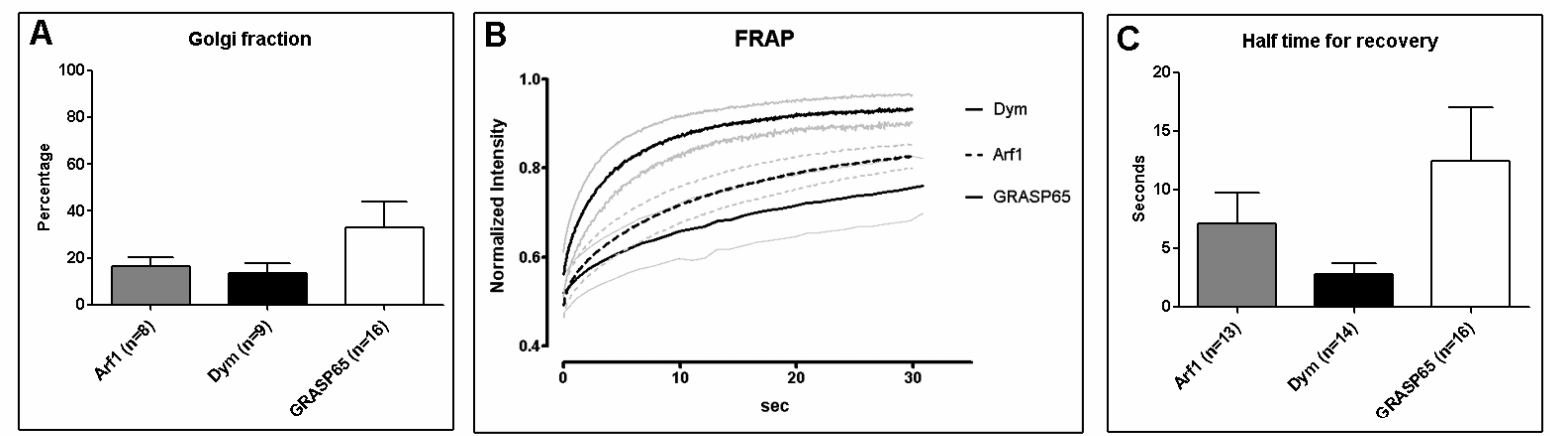

D
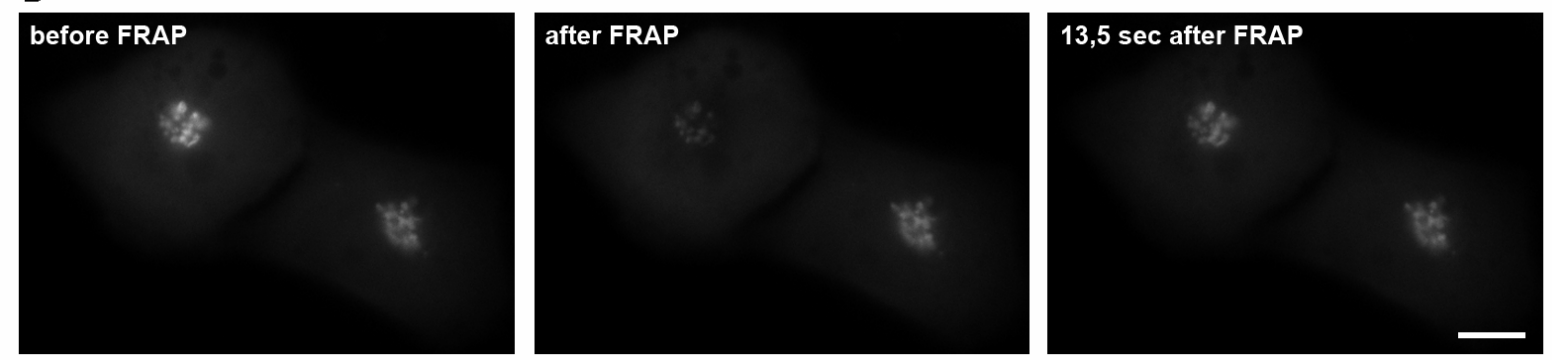

Figure 6, Dimitrov et al 

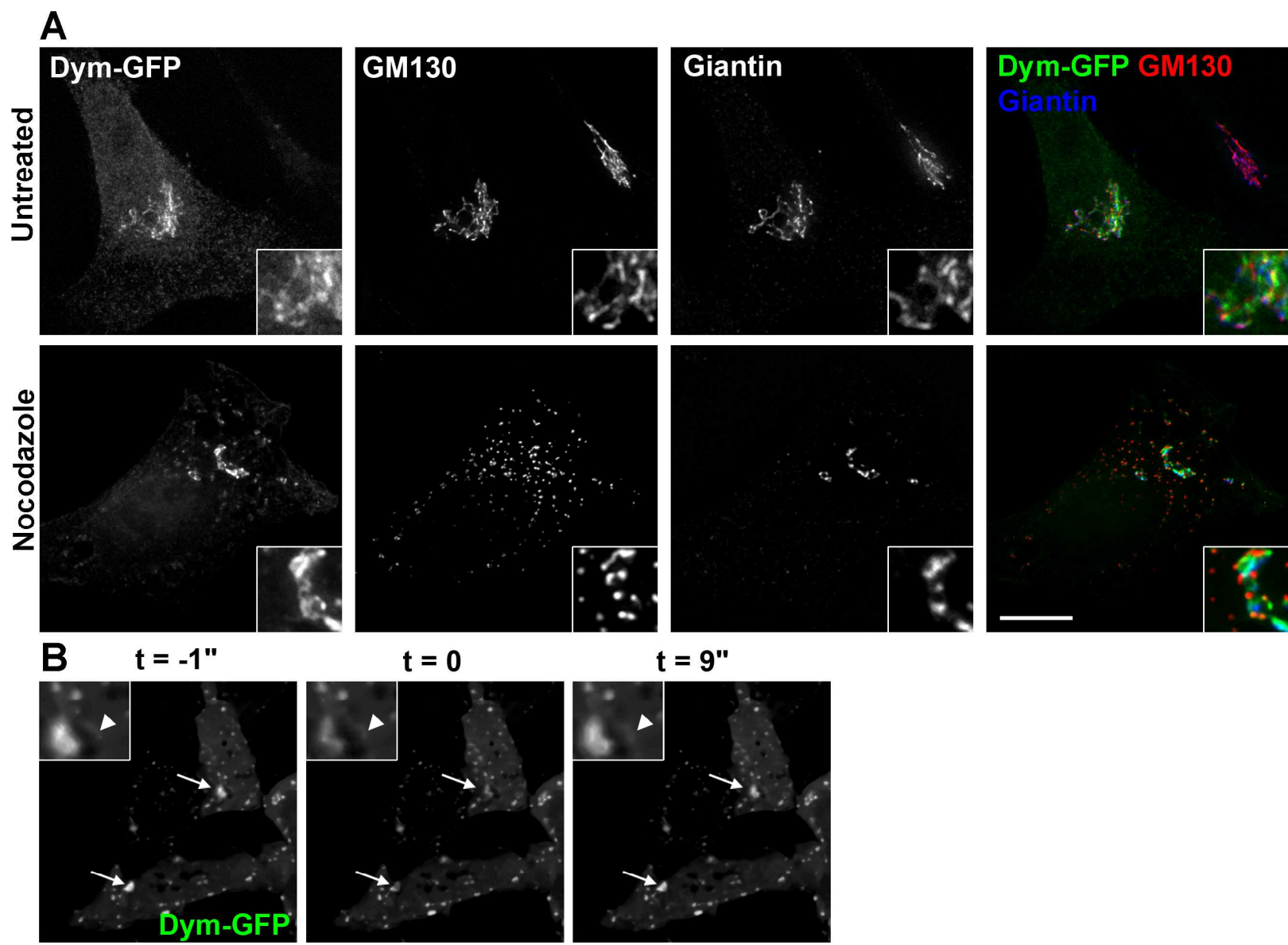

$t=9 "$
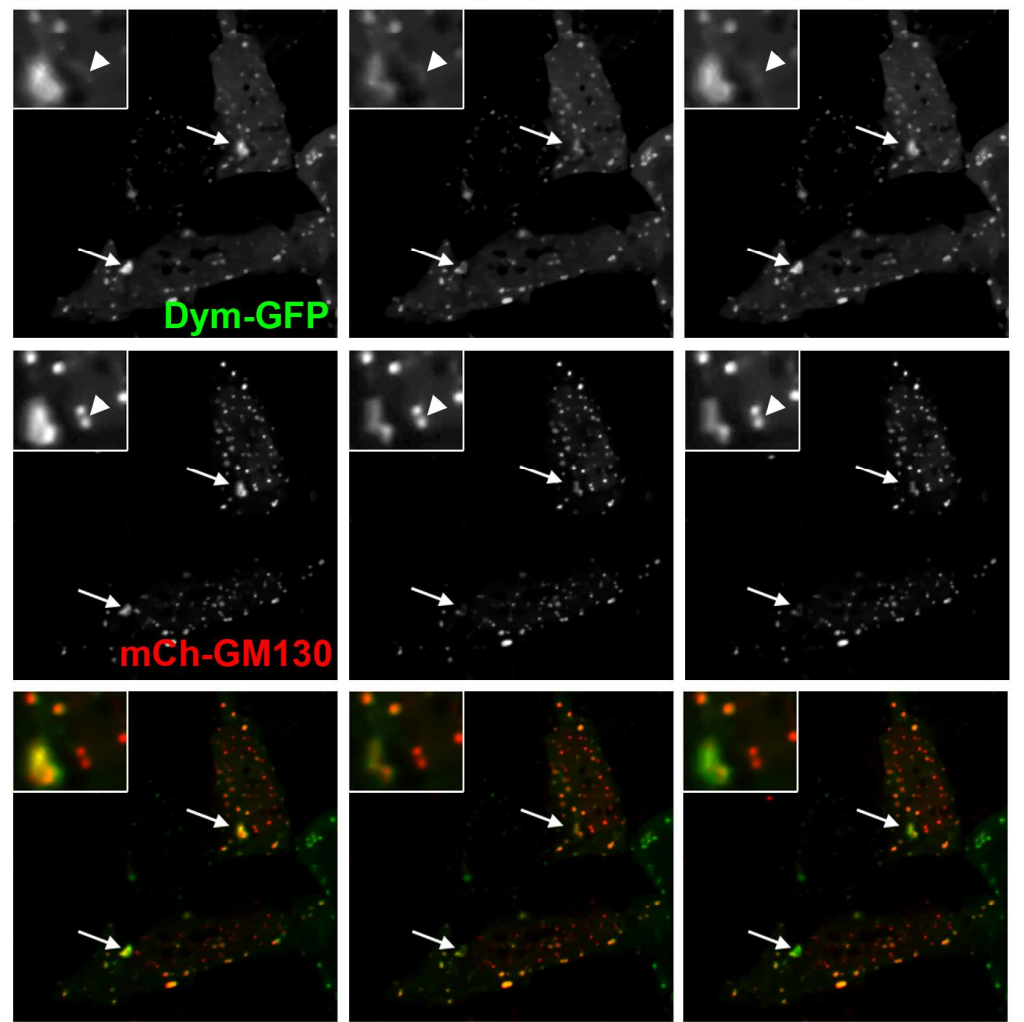

Figure 7, Dimitrov et al 

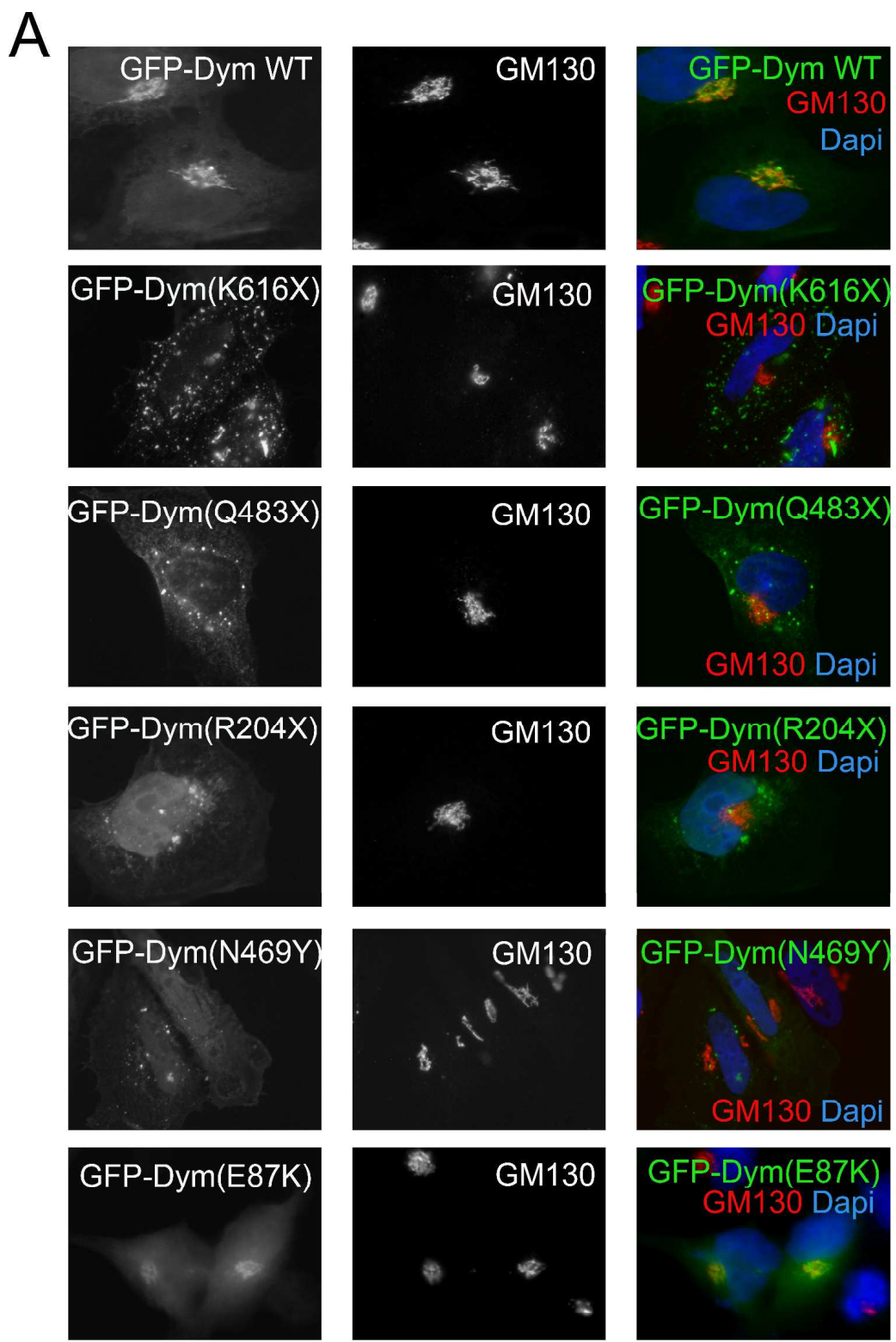

B
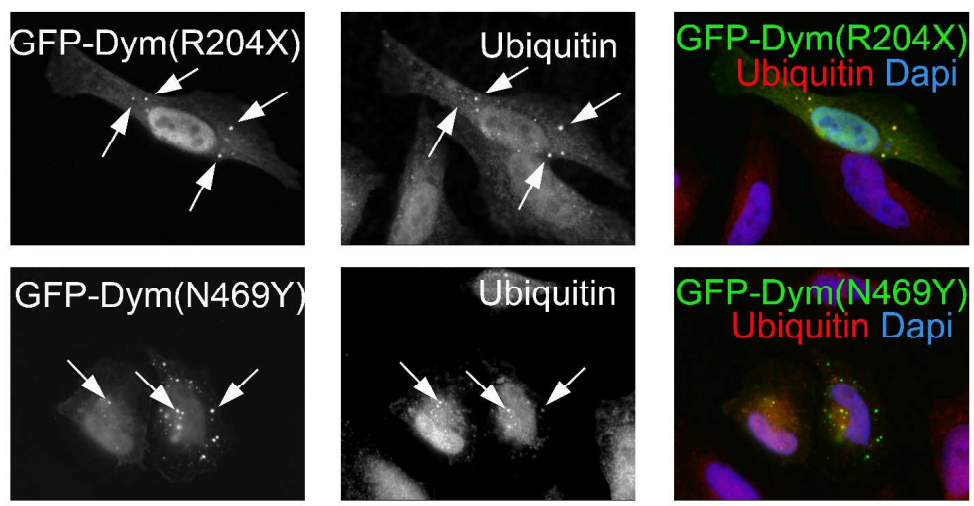

Figure 8, Dimitrov et al 


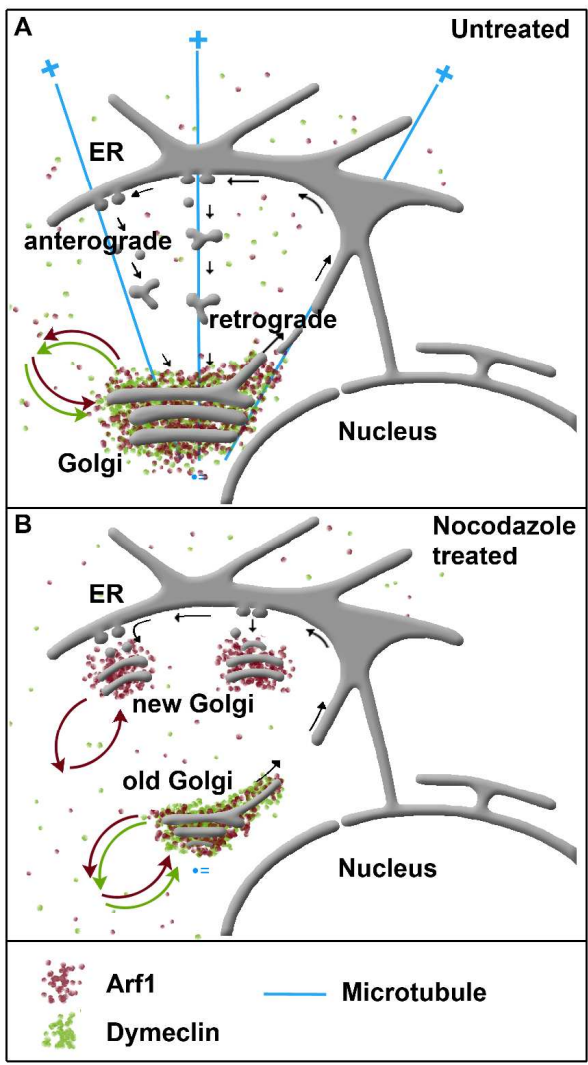

Figure 9, Dimitrov et al 